\title{
REFLEXÕES CONTEMPORÂNEAS PARA UMA EDUCAÇÃO ÉTICA E RESPONSÁVEL*
}

Cláudia Battestin ${ }^{1}$

Gomercindo Ghiggi ${ }^{2}$

Resumo:São muitos os argumentos e possibilidades de entrelaçar a Ética com a Educação, tentativa esta que já repercutiu em diversas áreas do conhecimento. Mas como é possível aproximar e interligar a Ética da Educação em pleno auge do desenvolvimento tecnológico do século XXI? Pensar nesta aproximação é compromisso de todas as áreas do saber, pois vivemos em um cenário globalizado, com acentuada centralidade da técnica e das novas demandas do mercado. A Educação poderá estar em sintonia com as mudanças de paradigmas, evitando a formação de identidades e mentalidades que podem levar mais uma vez o ser humano ao utilitarismo. A Ética inserida na Educação desenvolve no indivíduo a capacidade de estabelecer relações de responsabilidade, habilidades e criticidade nas ações. Dessa forma, argumentaremos a respeito da importância da abordagem da Ética universal e não reducionista. Hans Jonas e Paulo Freire contribuíram com seus escritos para destacar a importância da educação com princípios éticos universais, priorizando a vida em todas as esferas planetárias. É o que pretendemos mostrar neste texto.

Palavras-chave: Ética, Educação, Responsabilidade; Hans Jonas e Paulo Freire. 


\section{Educação e Ética: uma articulação necessária}

Em freqüentes debates acadêmicos surgem questionamentos sobre a responsabilidade do educador com os rumos da educação e do futuro. $\mathrm{O}$ educador Maturana afirma que

O educar se constitui no processo em que a criança ou o adulto convive com o outro e, ao conviver com o outro, se transforma espontaneamente, de maneira que seu modo de viver se faz progressivamente mais congruente com o do outro no espaço da convivência. O educar ocorre, portanto, todo o tempo e de maneira recíproca (MATURANA, 1999, p. 29).

A educação no ensino formal tem passado por significativos avanços no que tange à relação dialógica. Sem educando não existe educador e sem educador não existe educando. Mas para que tal diálogo ocorra é fundamental e necessário pensar e agir com sabedoria e principalmente com ética e responsabilidade. "O saber é o primeiro condicionante da relação pedagógica. Pela mediação do saber estabelece-se o contato entre aquele que o detém e recebeu a delegação social para transmiti-lo e aquele que deve adquiri-lo" (ESTRELA, 1998, p. 36-37).

O professor chileno Claudio Naranjo faz uma observação pertinente sobre a educação como possibilidade de mudanças. Em seu livro Cambiar la Educação para Cambiar el mundo, Naranjo (2007) assegura que a educação é o caminho para termos para a produção de uma sociedade melhor. Mas, para isso, necessitamos de pessoas com convicções para gerar mudanças. Naranjo (2007) defende a idéia de que, para termos uma sociedade viável e possível de viver com qualidade de vida, Educação, dignidade e, acima de tudo, felicidade, é preciso pensar na nossa espécie, no nosso planeta e cultivar nosso espírito. "Precisamos ajudar as pessoas a serem boas, logo então teremos um mundo bom" (id, p. 176).

Por outro lado, Boaventura de Souza Santos (2001) entende que a Educação tem um papel de conscientização esclarecedora das tendências atuais, sem, portanto, fechar-se em si mesma. Desta forma, a Educação teria a possibilidade de analisar as mudanças de paradigmas através de novas situações vividas. Sem dúvida, precisamos de paradigmas que superem o antropocentrismo, pois ainda vivemos em um estado transitório 
entre a ciência moderna e o novo paradigma cientifico, considerado por Santos (2001) ciência pós-moderna.

Outra abordagem que consideramos importante é sobre a responsabilidade da sociedade com a formação dos sujeitos. Para o educador Pedro Georgen, "as formas de pensar, sentir e julgar de crianças e jovens formam-se no contato com o meio no qual elas vivem e crescem (...) A sociedade, em seus diferentes ambientes, é responsável pela formação ética das futuras gerações" (GEORGEN, 2001, p. 83).

Dentro dessas breves reflexões interdisciplinares iniciais, percebemos que a educação está novamente sendo lembrada e chamada a contribuir e dialogar com a sociedade, particularmente sobre a responsabilidade que nós, sujeitos racionais, temos com o mundo. Essa idéia nos faz refletir sobre as possibilidades que a educação tem para amenizar os problemas do nosso tempo, bem como direcionar os seres humanos para um mundo digno de se viver.

Aproximar princípios éticos que visem a responsabilidade no âmbito educacional é poder construir uma adequada reflexão frente ao aumento do poder do homem com o meio em que vivemos. Destacaremos, portanto, reflexões acerca do pensamento de Hans Jonas e Paulo Freire. Ambos (educadores) escrevem sobre a proposta ética para um agir coletivo, pensando num processo educacional aberto para o mundo da vida, dos sujeitos históricos, de cidadãos conscientes e de educadores e educandos reflexivos, éticos e responsáveis.

\section{Contribuições de Hans Jonas e Paulo Freire para uma Educação com princípios éticos.}

Estamos vivendo um momento de crise, de mudanças, rupturas, momento de reflexão sobre as epidemias do mundo, sobre as crises mundiais e sobre a nossa condição humana. Nós, seres racionais, somos capazes de assumir a responsabilidade pela existência das gerações futuras? De gestar uma ética que compreenda todos os seres vivos como sendo da mesma esfera da nossa responsabilidade? Educar para a vida é um ato de amor, coragem e necessidade. Lutas, movimentos, propostas e teorias que indicam as possibilidades de mudança existem. O educador Paulo Freire e o filósofo Hans Jonas são exemplos que 
apontam para a possibilidade de superação de conceitos e teorias apontadas como certas, definitivas, prontas. Ambos viveram diferentes realidades, embora em países distantes, a partir de um princípio comum: a luta por uma ética universal.

Paulo Freire viveu desafiadores acontecimentos durante a ditadura militar no Brasil, afirmando que "um dia, proibido de ser, me vi longe de minha terra" (FREIRE, 2006, p. 50). Freire foi perseguido e preso por duas vezes, obrigado a deixar o Brasil no ano de 1964 rumo ao exílio na Bolívia e logo adiante no Chile, retornando ao Brasil somente no ano de 1980. Freire viveu desafiadoras experiências no exílio. Entre tantas, afirma:

Há algo que se nota, às vezes facilmente, na circunstância do exílio: como virtudes e defeitos são sublinhados. Enquanto situação-limite, o exílio nos provoca. É impossível passar por ele sem sermos testados em nossa capacidade de amar, de ter raiva, em nossa solidariedade ou fraqueza, em nossa capacidade de tolerar os diferentes, de ouvi-los, de respeitá-los (FREIRE, 2006, p. 52).

Com as experiências vividas por Freire durante o exílio surgiram inquietações sobre a educação, sobre a vida, sobre os pobres e os oprimidos. Paulo Freire contribuiu muito com suas concepções a respeito da educação ética, solidária, transformadora e libertadora.

Em outro continente, Hans Jonas também viveu experiências existenciais profundas nos campos de batalha durante a II Guerra Mundial. No ano de 1934, Jonas abandona a Alemanha devido à ascensão do Nazismo ao poder e alista-se no Exército britânico, lutando durante cinco anos contra Hitler. Neste período, Jonas reflete sobre a vida com a proximidade da morte, voltando a sua atenção para as questões éticas suscitadas pelo progresso da tecnologia. Hans Jonas foi um pensador (educador) que remeteu suas preocupações com a humanidade, com a vida presente e futura. Seus pensamentos e escritos envolveram a ética, a vida e a humanidade. Hans Jonas torna-se, assim, uma referência para a Bioética, a Educação e a Filosofia, desafiando questões acerca de como educar os humanos em tempos de crise.

Ante a urgência de discutir a respeito dos rumos da educação, enfatizando o desafio de como educar para uma vida viável, Jonas 
contribuiu buscando alternativas para um mundo melhor, por meio de uma prática pedagógica que toma a ética e a responsabilidade como temas emergentes e centrais.

Tanto Freire como Jonas viveram desafiadoras experiências durante o Século XX. Ambos assumiram como prioridade o respeito e a luta por uma vida digna e por um mundo justo de se viver. Para os autores, a ética universal é uma práxis coletiva que necessita de sujeitos responsáveis que priorizem a vida, o respeito, os direitos e os deveres como formas de valorizar o ser humano frente aos abusos da técnica moderna.

Para Jonas (2006), a essência da responsabilidade tem propriedades que não pouco ultrapassam a incumbência da Educação. Jonas aposta na Ética não refém do individualismo, mas centrada na consciência coletiva. E para que isso ocorra será necessária uma participação efetiva de todos envolvidos no processo de formação e educação dos sujeitos, iniciando pela responsabilidade paterna e política. Somente assim poderemos falar em agir ético e responsável na esfera da Educação.

Para Paulo Freire, é essencialmente importante que o ser humano se reconheça como sujeito da sua própria história. Freire afirma que: "assumirmo-nos como sujeitos e não objetos da História nos torna seres da decisão, da ruptura. Seres éticos" (FREIRE, 2001, p.40). É fundamental refletirmos sobre as concepções acerca da educação argumentadas por Paulo Freire, pois as mesmas possibilitam reconhecer que somente na condição de sujeitos históricos poderemos nos tornar seres éticos. "O que, sobretudo, me move a ser ético é saber que, sendo a educação, por sua própria natureza, diretiva e política, eu devo, sem jamais negar meu sonho ou minha utopia aos educandos, respeitálos" (FREIRE, 2002, p. 78). Paulo Freire defende a universalidade de uma ética nos seguintes termos:

Quando falo, porém, da ética universal do ser humano estou falando da ética enquanto marca da natureza humana enquanto algo absolutamente indispensável à convivência humana. Ao fazêlo estou advertido das possíveis críticas que, infiéis ao meu pensamento, me apontarão como ingênuo e idealista. Na verdade falo da ética universal do ser humano da mesma forma como falo de sua vocação ontológica para o ser mais, como de sua natureza constituindo-se social e historicamente (FREIRE, 1996, p. 20). 
É fundamental que em toda prática e teoria possamos fundamentar os princípios freireanos, relacionando os sujeitos históricos com a sociedade. Desta forma poderemos analisar a tarefa educativa não como sendo de responsabilidade exclusiva do ensino formal, mas de todos os sujeitos envolvidos no processo histórico. Freire enfatiza, também, a importância da educação para a diversidade, respeitando as diferentes culturas e realidades vividas. $\mathrm{O}$ ato de educar para Freire é um ato de respeito e seriedade, tendo como princípio permanente o agir ético em todas as ações. Freire esclarece a importância da Ética na Educação da seguinte forma:

Gostaria, por outro lado, de sublinhar a nós mesmos, professores e professoras, a nossa responsabilidade ética no exercício de nossa tarefa docente. Este pequeno livro se encontra cortado ou permeado em sua totalidade pelo sentido da necessária eticidade que conota expressivamente a natureza da prática educativa, enquanto prática formadora. Educadores e educandos não podemos, na verdade, escapar à rigorosidade ética. Mas, é preciso deixar claro que a ética de que falo não é a ética menor, restrita, do mercado, que se curva obediente aos interesses do lucro (...) falo da Ética universal dos seres humanos, que condena o cinismo, que condena a exploração da força de trabalho do ser humano (FREIRE, 1996, p. 16-17).

A ética antropocêntrica é criticada por Freire, pois seria um privilégio de poucos e um ato egoísta pensar em seus próprios interesses. A ética universal possibilita vínculos de interesses coletivos e amplos. Somente com a ética universal poderemos atuar a favor de mudanças radicais na sociedade em que vivemos. Mas para que possamos romper com a idéia utilitarista que permeia e condena muitas vezes a nossa atual sociedade capitalista, precisamos de uma articulação permanente entre educandos e educadores, para que possamos nos incumbir da rigorosidade ética.

Por sua vez, Hans Jonas rompe com as bases da ética antropocêntrica e propõe, também, a ética universal com o seu O Princípio Responsabilidade, a fim de abranger todas as formas de vida da biosfera. A teoria da responsabilidade poderá nos ajudar a levantar questões que poderão contribuir para uma Educação Ética. 
Conforme Jonas escreveu no livro Técnica, medicina e ética,

Nem uma ética anterior tinha de levar em consideração a condição global da vida humana e o futuro distante e até mesmo a existência da espécie. Com a consciência de extrema vulnerabilidade da natureza a intervenção tecnológica do homem, surge a ecologia. Repensar os princípios básicos daética. Procurar não só o bem humano, mas também o bem de coisas - extra-humanas, ou seja, alargar o conhecimento dos "fins em si mesmos" para além da esfera do homem, e fazer com que o bem humano incluísse o cuidado delas (JONAS, 1997, p. 40).

As doutrinas éticas tradicionais carecem de uma série de atualizações especialmente na medida em que partem das reflexões sobre a condição humana que a modernidade ultrapassou: "quando se aplica à ética liberal, usamos instrumentos antigos e insuficientes para lidar com todos os efeitos negativos e os novos desafios da civilização, seja em termos locais ou globais" (PELIZZOLI, 2003, p. 98).

Hans Jonas iniciou suas reflexões éticas a partir das vivências de desumanização das quais participou, bem como da exploração meio ambiente pelo homem no decorrer dos tempos. Jonas aponta as exigências da ética nos seguintes termos:

Hoje, a ética tem a ver com atos que têm um alcance causal incomparável em direção ao futuro, e que são acompanhados de um saber de previsão que, independentemente do seu caráter incompleto, vai muito além, do que se conhecia antigamente. É preciso acrescentar à simples ordem de grandeza das ações a longo termo, freqüentemente a sua irreversibilidade. Tudo isso coloca a responsabilidade no centro da ética, inclusive os horizontes de espaço e tempo que correspondem aos das ações (JONAS, 1995, p.17).

A ética que Hans Jonas aborda, como ética da responsabilidade, é uma área do conhecimento que se aproxima da bioética, pois prioriza a vida como sendo de plena responsabilidade humana. Hans Jonas determinou O Principio Responsabilidade como sendo uma ética em que o mundo animal, vegetal, mineral, biosfera e estratosfera passam a fazer parte da esfera da responsabilidade. A reflexão sobre a incerteza da vida futura é um sinal de que houve um equívoco cometido ao isolar 
o ser humano do restante da Natureza (sendo o homem a própria Natureza). Somente uma ética fundamentada na amplitude do ser poderia ter um significado real e verdadeiro das coisas. Segundo o autor, para "ser é necessário existir, e para existir é necessário viver e ter deveres, porém, (...) somente uma ética fundada na amplitude do Ser pode ter significado" (JONAS, 2006, p. 17).

Para debatermos assuntos emergentes, como os temas educacionais, necessitamos pensar na construção de uma ética coletiva e universal, que supere o utilitarismo e o antropocentrismo. Entretanto, é importante assumirmos o trabalho com princípios éticos e reflexivos a fim de indagar sobre a radicalidade dos problemas, propondo soluções e alternativas sustentáveis para a vida. A Educação, quando parceira da Filosofia (Ética), tem condições de realizar a emancipação dessa racionalidade, proporcionando um processo de ensino aprendizagem que tenha como princípio ético a responsabilidade.

O Princípio Responsabilidade é um imperativo ético que visa um debate acerca da problemática ambiental do nosso tempo. No entanto, poderíamos indagar: como é possível educar com princípios éticos e responsáveis no contexto de perversidades no qual vivemos? Normalmente, entende-se que é um dever de toda a sociedade educar visando à responsabilidade. Iniciando pelas convicções pessoais e condutas particulares, passando pela família, pela escola, pela comunidade, pelos órgãos privados e públicos e pela gestão política que administra a organização da sociedade. Educar em tempos de crise é um desafio para quem ensina e para quem aprende. Por isso, é fundamental questionar sobre as razões que nos levam a refletir sobre a vida.

Para o educador Paulo Freire, é possível uma educação ética, desde que todos estejam envolvidos no processo educativo e engajados na luta por uma educação transformadora. No processo de construção do conhecimento tal se dá quando todos ensinam e aprendem com suas próprias experiências e histórias de vida. Por isso Paulo Freire lutou por uma ética da diversidade, pois a sociedade deve educar o ser humano para a vida, para os valores, a fim de despertar ações visando a proteção e o respeito à biosfera.

Paulo Freire e Hans Jonas não viveram a intensidade dos avanços da tecnologia dos últimos quinze anos. Porém, percebemos nos escritos 
de Jonas o quanto suas previsões apontavam para o agravamento e à amplitude da relação dos impactos da ação do homem com o meio. Isso nos remete a pensar que se Freire e Jonas estivessem entre nós, a luta pela vida continuaria, partindo da indignação e da "justa raiva" (Freire) ou dos princípios próprias da ética e da responsabilidade.

Pensar na existência é poder pensar nas possibilidades de estarmos "com e no mundo". Se estamos "no mundo" estamos como seres em existência, mas se estamos "com o mundo" estamos na luta pela vida e nos tornaremos testemunhas de nossa própria história. Por isso Freire lembra: "Com a palavra, o homem se faz homem. Ao dizer sua palavra, pois, o homem assume conscientemente sua essencial condição humana" (FREIRE, 1980, p.7). Precisamos ir ao encontro das idéias de Freire. Precisamos educar para a vida, problematizando o ser humano na sua relação com o mundo. Freire argumenta claramente como é importante poder manifestar-se para poder transformar. "A existência, porque humana, não pode ser muda, silenciosa, nem tampouco pode nutrir-se de falsas palavras, mas de palavras verdadeiras, com que os homens transformam o mundo" (FREIRE, 1980, p. 92). O ser humano, como existência, não se torna sujeito de investigação, mas, como essência, torna-se sujeito capaz de refletir criticamente sobre a sua condição humana.

Para o animal, rigorosamente, não há um aqui, um agora, um ali, um amanhã, um ontem, porque carecendo da consciência de si, seu viveré uma determinação total. Nãoé possível ao animal sobrepassar os limites impostos pelo aqui, pelo agora ou pelo ali (FREIRE, 1980, p. 106).

Os animais não admiram o mundo, apenas vivem nele. Por isso a condição irracional não é responsável pelo futuro da humanidade. Mas nós somos responsáveis pelo futuro dos irracionais. Para Freire (1980), a questão fundamental que carece ser trabalhada sempre é a compreensão crítica da "totalidade das coisas", sua interação na totalidade do Planeta Terra. E, para poder transformar, é ontológico o diálogo, pois “o diálogo, como encontro dos homens para a pronúncia do mundo, é uma condição fundamental para a sua real humanização" (FREIRE, 1980, p. 160).

O grande desafio está em poder repensar a educação numa perspectiva emancipatória, enfrentando a fragmentação do conhecimento e a 
conservação de estruturas sociais injustas, fundamentadas em heranças autoritárias. Freire argumenta que precisamos de mudanças educacionais, principalmente no Brasil:

Precisamos hoje no Brasil, talvez mais do que ontem, de uma prática educativa exemplarmente democrática. Precisamos de campanhas realizadas, por exemplo, através de semanas de estudos da democracia em escolas públicas, privadas, universidades, escolas técnicas, sindicatos. Campanhas que encharcassem as cidades de democracia. Semanas em que se apresentasse a história da democracia, em que se debatesse a relação entre democracia e ética, e classes populares, e economia. Eleições, direitos e deveres que elas implicam. Inexperiência democrática brasileira. Democracia e tolerância. Gosto da liberdade e democracia; forças inconciliavelmente contraditórias; forças conciliavelmente diferentes; unidade da diversidade (FREIRE, 2006, p.73).

Paulo Freire sempre ressaltou a importância da participação nas lutas e movimentos sociais, pois essas experiências ajudariam a mudar a compreensão dos fatos. Por isso é fundamental continuar apostando numa educação responsável, que desempenhe o seu papel na sociedade, abrindo espaços de discussões em que sejam explicitadas e analisadas as concepções presentes na atual realidade. Somente assim poderemos construir uma cidadania que privilegie o conhecimento, apontando para a possibilidade de uma maior liberdade e autonomia. A educação, afirma Freire (2006), não pode tudo, mas sem ela a mudança torna-se mais difícil.

Se a educação sozinha não transforma a sociedade, sem ela tampouco a sociedade muda. Se a nossa opção é progressista, se estamos a favor da vida e não da morte, da equidade e não da injustiça, do direito e não do arbítrio, da convivência com o diferente e não de sua negação, não temos outro caminho senão viver plenamente a nossa opção. Encarná-la, diminuindo assim a distância entre o que fizemos e o que fazemos. Desrespeitando os fracos, enganando os incautos, ofendendo a vida, explorando os outros, discriminando o índio, o negro, a mulher não estarei ajudando meus filhos a serem sérios, justos e amorosos da vida e dos outros (FREIRE, 2000, p. 31-32). 
Portanto, é através de uma Educação engajada, com princípios éticos, que o ser humano poderá tornar-se um sujeito consciente e comprometido com as causas emergentes e necessárias para educarmos em tempos de "crise". Mas, para que isso ocorra, é preciso envolver as pessoas, pois a tarefa e o caminho a serem seguidos serão de luta e persistência. É neste emaranhado de certezas e incertezas que nasce a cada dia uma nova esperança, em lugares diferentes, com pessoas diferentes, mas com realidades e preocupações de vida em comum.

Precisamos saber e denunciar as realidades constitutivas de um mundo desumanizado. Freire é exemplo para que possamos continuar lutando e acreditando nas possíveis mudanças e não identificar as grandes causas como luta utópica. O educador Paulo Freire lutou a favor de uma educação solidária e transformadora, tanto que suas idéias se propagaram em todo Brasil e pelo mundo afora. Freire sonhou os bons sonhos e muitos deles foram concretizados. Por isso retomamos Freire para pensar o atual quadro da educação.

Acompanhados de Paulo Freire e Hans Jonas, precisamos de uma educação que problematize e mostre a importância dos sujeitos no mundo e com o mundo; que estimule a reflexão dos sujeitos acerca das realidades vividas, que giram em torno de corrupção, da alienação, e que aposte na valorização de todos os sujeitos envolvidos. Quanto mais problematizarmos e orientarmos o mundo vivido, mais reforçaremos a necessidade de uma educação ética e responsável.

\section{Finalizando...}

Tanto Freire quanto Jonas entendem a ética como um saber que pode ser ensinado e aprendido. Sabemos que a ética e a educação não vão transformar o mundo, mas a transformação não é possível sem a ética e sem a educação. Ou seja, "se a educação quer realmente transformar a realidade não basta intervir na mudança dos comportamentos sem intervir nas condições do mundo em que as pessoas habitam" (CARVALHO, 1992, p. 33).

A reflexão ética na educação implica em poder construir conhecimentos, conceitos e paradigmas. Desta forma, repensar o papel da ética no contexto educacional é primordial. É preciso pensar a ética 
como um conhecimento que deverá ser agregado ao ato de educar. A ética é "a própria essência do ato educativo" (GADOTTI, 2000, p. 81). Precisamos repensar os modelos de sociedades que prevalecem como sendo certos em nosso tempo, bem como sobre o posicionamento das instituições de ensino acerca da educação em tempos de crise.

A tarefa é educar cidadãos capazes de questionar e fundamentar valores radicalmente críticos e éticos. Por isso vai se tornando imperativo aprender a educar visando o processo histórico como umas das explicações sobre o passado, vivendo o presente e pensando o futuro. Por isso, as célebres palavras de Freire servem como uma reflexão a ser feita todos os dias enquanto estivermos na luta: "a educação é indispensável nessa reinvenção. Assumirmo-nos como sujeitos e objetos da História nos torna seres da decisão da ruptura. Seres éticos" (FREIRE, 2006, p. 40).

A tarefa e o caminho a serem seguidos são longos e demandam persistência. Nós, enquanto educadores, temos um compromisso com a educação diante de todas as questões, principalmente as questões sociais e éticas, para que possamos educar para a mudança de compreensão e de ação. É necessário fazer uma reflexão sobre o ato de educar, considerando as divergências em torno do atual debate que cerca o tema da ética. Neste contexto percebemos a importância das discussões próprias da modernidade nas atuais discussões acerca dos rumos da civilização contemporânea. Para Jonas (2006), quanto mais se pressente o perigo do futuro, mais temos que agir no presente. E este é o nosso desafio: educar para a vida.

\section{Notas}

\footnotetext{
"Esse artigo tem origem nos estudos de Mestrado em Educação, realizados por Cláudia Battestin, sob a orientação do Professor Gomercindo Ghiggi, pelo PPGE da UFPel.

${ }^{1}$ Doutoranda em Educação pela UFPel. Mestre em Educação pela UFPel. Especialista em Educação Ambiental pela UFSM. Licenciada em Filosofia pela UNOCHAPECÓ. Participa do Grupo de Pesquisa - Filosofia, Educação e Práxis Social e da Linha de Pesquisa: Filosofia e História da Educação do PPGE da UFPel, E-mail: claudiabattestin@ hotmail.com

${ }^{2}$ Doutor em Educação pela UFRGS. Mestre em Antropologia Filosófica pela PUCRS e Graduado em Filosofia pela UCPel. Participa do Grupo de Pesquisa - Filosofia, Educação e Práxis Social e da Linha de Pesquisa: Filosofia e História da Educação do PPGE da UFPel. Professor do Programa de Pós-Graduação em Educação (Mestrado e Doutorado) da Universidade Federal de Pelotas (UFPel). E-mail: gghiggi@terra.com.br
} 


\section{Referências}

CARVALHO, I.C.M. Educação, meio ambiente e ação política. Rio de Janeiro: IBASE ,1992.

ESTRELA, M. T. Relação pedagógica, disciplina e indisciplina na aula. 3 ed. Porto: Porto Editora, 1998.

FREIRE, Paulo. A sombra desta Mangueira. 8 ed. São Paulo: Olho d'Água, 2006.

. Pedagogia da Indignação. Cartas pedagógicas e outros escritos. São Paulo: UNESP, 2000.

. Educação como prática da liberdade. $25^{\mathrm{a}}$ ed. Rio de Janeiro: Paz e Terra, 2001.

Pedagogia da esperança: um reencontro com a Pedagogia do oprimido. 9. ed. Rio de Janeiro: Paz e Terra, 2002.

- Pedagogia da Autonomia: saberes necessários à prática educativa, 30 ed. Rio de Janeiro: Paz e Terra, 1996.

.Pedagogia do Oprimido. 8 ed. Rio de Janeiro: Paz e Terra, 1980.

.Técnica, medicina y ética. Barcelona: Paidós, 1997.

GADOTTI, M. Educação e poder: introdução à pedagogia do conflito. São Paulo: Cortez, 1988.

GEORGEN, Pedro. Pós-modernidade, ética e educação: polêmicas do nosso tempo. Campinas: Autores associados, 2001.

JONAS, Hans. El principio del responsabilidad: ensayo de una ética para la civilización tecnológica. Barcelona: Herder, 1995. 
. O Princípio Responsabilidade. Ensaio de uma ética para uma civilização tecnológica. Rio de Janeiro: PUC Rio, 2006

MATURANA, Humberto. Emoções e Linguagem na Educação e na Política. Belo Horizonte, Editora UFMG. 1999.

NARANJO, Cláudio. Cambiar la educacion para cambiar el mundo. Providencia:Cuarto proprio, 2007.

SANTOS, Boaventura de Sousa Os Processos da globalização. Porto: Edições Afrontamento, 2001.

\section{Abstract: \\ Contemporaries reflexions for an ethical and responsible education}

There are many arguments and possibilities to interlace Ethics with Education. However, this attempt has already reverberated in many areas of knowledge. But how it is possible to near and link the Ethics in Education in the peak of technological development of the XXI century? But how it is possible to approach and connect the Ethics in Education in the peak of technological development of the XXI century? Think in this approach it is a commitment of all the knowledge areas, because we live in a globalized scenario, where everything turns around the technique and the new demands of the market. However, the education could be in tune with the changes of paradigms, avoiding the formation and attitudes that can lean the human being to utilitarianism once more. The Ethics inserted in Education develops in the individual the capacities to establish relationships of responsibility, skills and criticism in actions. By this way, we will argue in respect of the importance in address the Ethics in a universal form and not in the reductionist form. Hans Jonas and Paulo Freire contributed with their writings about the importance in teaching with universal ethics principles, prioritizing the life in all planetary spheres.

Key-Words: Ethics. Education. Responsibility. Hans Jonas and Paulo Freire.

Recebido em agosto de 2009.

Aceito em dezembro de 2009. 


\section{REFLEXÕES CONTEMPORÂNEAS PARA UMA EDUCAÇÃO ÉTICA E RESPONSÁVEL*}

Cláudia Battestin ${ }^{1}$

Gomercindo Ghiggi ${ }^{2}$

Resumo:São muitos os argumentos e possibilidades de entrelaçar a Ética com a Educação, tentativa esta que já repercutiu em diversas áreas do conhecimento. Mas como é possível aproximar e interligar a Ética da Educação em pleno auge do desenvolvimento tecnológico do século XXI? Pensar nesta aproximação é compromisso de todas as áreas do saber, pois vivemos em um cenário globalizado, com acentuada centralidade da técnica e das novas demandas do mercado. A Educação poderá estar em sintonia com as mudanças de paradigmas, evitando a formação de identidades e mentalidades que podem levar mais uma vez o ser humano ao utilitarismo. A Ética inserida na Educação desenvolve no indivíduo a capacidade de estabelecer relações de responsabilidade, habilidades e criticidade nas ações. Dessa forma, argumentaremos a respeito da importância da abordagem da Ética universal e não reducionista. Hans Jonas e Paulo Freire contribuíram com seus escritos para destacar a importância da educação com princípios éticos universais, priorizando a vida em todas as esferas planetárias. É o que pretendemos mostrar neste texto.

Palavras-chave: Ética, Educação, Responsabilidade; Hans Jonas e Paulo Freire. 


\section{Educação e Ética: uma articulação necessária}

Em freqüentes debates acadêmicos surgem questionamentos sobre a responsabilidade do educador com os rumos da educação e do futuro. $\mathrm{O}$ educador Maturana afirma que

O educar se constitui no processo em que a criança ou o adulto convive com o outro e, ao conviver com o outro, se transforma espontaneamente, de maneira que seu modo de viver se faz progressivamente mais congruente com o do outro no espaço da convivência. O educar ocorre, portanto, todo o tempo e de maneira recíproca (MATURANA, 1999, p. 29).

A educação no ensino formal tem passado por significativos avanços no que tange à relação dialógica. Sem educando não existe educador e sem educador não existe educando. Mas para que tal diálogo ocorra é fundamental e necessário pensar e agir com sabedoria e principalmente com ética e responsabilidade. "O saber é o primeiro condicionante da relação pedagógica. Pela mediação do saber estabelece-se o contato entre aquele que o detém e recebeu a delegação social para transmiti-lo e aquele que deve adquiri-lo" (ESTRELA, 1998, p. 36-37).

O professor chileno Claudio Naranjo faz uma observação pertinente sobre a educação como possibilidade de mudanças. Em seu livro Cambiar la Educação para Cambiar el mundo, Naranjo (2007) assegura que a educação é o caminho para termos para a produção de uma sociedade melhor. Mas, para isso, necessitamos de pessoas com convicções para gerar mudanças. Naranjo (2007) defende a idéia de que, para termos uma sociedade viável e possível de viver com qualidade de vida, Educação, dignidade e, acima de tudo, felicidade, é preciso pensar na nossa espécie, no nosso planeta e cultivar nosso espírito. "Precisamos ajudar as pessoas a serem boas, logo então teremos um mundo bom" (id, p. 176).

Por outro lado, Boaventura de Souza Santos (2001) entende que a Educação tem um papel de conscientização esclarecedora das tendências atuais, sem, portanto, fechar-se em si mesma. Desta forma, a Educação teria a possibilidade de analisar as mudanças de paradigmas através de novas situações vividas. Sem dúvida, precisamos de paradigmas que superem o antropocentrismo, pois ainda vivemos em um estado transitório 
entre a ciência moderna e o novo paradigma cientifico, considerado por Santos (2001) ciência pós-moderna.

Outra abordagem que consideramos importante é sobre a responsabilidade da sociedade com a formação dos sujeitos. Para o educador Pedro Georgen, "as formas de pensar, sentir e julgar de crianças e jovens formam-se no contato com o meio no qual elas vivem e crescem (...) A sociedade, em seus diferentes ambientes, é responsável pela formação ética das futuras gerações" (GEORGEN, 2001, p. 83).

Dentro dessas breves reflexões interdisciplinares iniciais, percebemos que a educação está novamente sendo lembrada e chamada a contribuir e dialogar com a sociedade, particularmente sobre a responsabilidade que nós, sujeitos racionais, temos com o mundo. Essa idéia nos faz refletir sobre as possibilidades que a educação tem para amenizar os problemas do nosso tempo, bem como direcionar os seres humanos para um mundo digno de se viver.

Aproximar princípios éticos que visem a responsabilidade no âmbito educacional é poder construir uma adequada reflexão frente ao aumento do poder do homem com o meio em que vivemos. Destacaremos, portanto, reflexões acerca do pensamento de Hans Jonas e Paulo Freire. Ambos (educadores) escrevem sobre a proposta ética para um agir coletivo, pensando num processo educacional aberto para o mundo da vida, dos sujeitos históricos, de cidadãos conscientes e de educadores e educandos reflexivos, éticos e responsáveis.

\section{Contribuições de Hans Jonas e Paulo Freire para uma Educação com princípios éticos.}

Estamos vivendo um momento de crise, de mudanças, rupturas, momento de reflexão sobre as epidemias do mundo, sobre as crises mundiais e sobre a nossa condição humana. Nós, seres racionais, somos capazes de assumir a responsabilidade pela existência das gerações futuras? De gestar uma ética que compreenda todos os seres vivos como sendo da mesma esfera da nossa responsabilidade? Educar para a vida é um ato de amor, coragem e necessidade. Lutas, movimentos, propostas e teorias que indicam as possibilidades de mudança existem. O educador Paulo Freire e o filósofo Hans Jonas são exemplos que 
apontam para a possibilidade de superação de conceitos e teorias apontadas como certas, definitivas, prontas. Ambos viveram diferentes realidades, embora em países distantes, a partir de um princípio comum: a luta por uma ética universal.

Paulo Freire viveu desafiadores acontecimentos durante a ditadura militar no Brasil, afirmando que "um dia, proibido de ser, me vi longe de minha terra" (FREIRE, 2006, p. 50). Freire foi perseguido e preso por duas vezes, obrigado a deixar o Brasil no ano de 1964 rumo ao exílio na Bolívia e logo adiante no Chile, retornando ao Brasil somente no ano de 1980. Freire viveu desafiadoras experiências no exílio. Entre tantas, afirma:

Há algo que se nota, às vezes facilmente, na circunstância do exílio: como virtudes e defeitos são sublinhados. Enquanto situação-limite, o exílio nos provoca. É impossível passar por ele sem sermos testados em nossa capacidade de amar, de ter raiva, em nossa solidariedade ou fraqueza, em nossa capacidade de tolerar os diferentes, de ouvi-los, de respeitá-los (FREIRE, 2006, p. 52).

Com as experiências vividas por Freire durante o exílio surgiram inquietações sobre a educação, sobre a vida, sobre os pobres e os oprimidos. Paulo Freire contribuiu muito com suas concepções a respeito da educação ética, solidária, transformadora e libertadora.

Em outro continente, Hans Jonas também viveu experiências existenciais profundas nos campos de batalha durante a II Guerra Mundial. No ano de 1934, Jonas abandona a Alemanha devido à ascensão do Nazismo ao poder e alista-se no Exército britânico, lutando durante cinco anos contra Hitler. Neste período, Jonas reflete sobre a vida com a proximidade da morte, voltando a sua atenção para as questões éticas suscitadas pelo progresso da tecnologia. Hans Jonas foi um pensador (educador) que remeteu suas preocupações com a humanidade, com a vida presente e futura. Seus pensamentos e escritos envolveram a ética, a vida e a humanidade. Hans Jonas torna-se, assim, uma referência para a Bioética, a Educação e a Filosofia, desafiando questões acerca de como educar os humanos em tempos de crise.

Ante a urgência de discutir a respeito dos rumos da educação, enfatizando o desafio de como educar para uma vida viável, Jonas 
contribuiu buscando alternativas para um mundo melhor, por meio de uma prática pedagógica que toma a ética e a responsabilidade como temas emergentes e centrais.

Tanto Freire como Jonas viveram desafiadoras experiências durante o Século XX. Ambos assumiram como prioridade o respeito e a luta por uma vida digna e por um mundo justo de se viver. Para os autores, a ética universal é uma práxis coletiva que necessita de sujeitos responsáveis que priorizem a vida, o respeito, os direitos e os deveres como formas de valorizar o ser humano frente aos abusos da técnica moderna.

Para Jonas (2006), a essência da responsabilidade tem propriedades que não pouco ultrapassam a incumbência da Educação. Jonas aposta na Ética não refém do individualismo, mas centrada na consciência coletiva. E para que isso ocorra será necessária uma participação efetiva de todos envolvidos no processo de formação e educação dos sujeitos, iniciando pela responsabilidade paterna e política. Somente assim poderemos falar em agir ético e responsável na esfera da Educação.

Para Paulo Freire, é essencialmente importante que o ser humano se reconheça como sujeito da sua própria história. Freire afirma que: "assumirmo-nos como sujeitos e não objetos da História nos torna seres da decisão, da ruptura. Seres éticos" (FREIRE, 2001, p.40). É fundamental refletirmos sobre as concepções acerca da educação argumentadas por Paulo Freire, pois as mesmas possibilitam reconhecer que somente na condição de sujeitos históricos poderemos nos tornar seres éticos. "O que, sobretudo, me move a ser ético é saber que, sendo a educação, por sua própria natureza, diretiva e política, eu devo, sem jamais negar meu sonho ou minha utopia aos educandos, respeitálos" (FREIRE, 2002, p. 78). Paulo Freire defende a universalidade de uma ética nos seguintes termos:

Quando falo, porém, da ética universal do ser humano estou falando da ética enquanto marca da natureza humana enquanto algo absolutamente indispensável à convivência humana. Ao fazêlo estou advertido das possíveis críticas que, infiéis ao meu pensamento, me apontarão como ingênuo e idealista. Na verdade falo da ética universal do ser humano da mesma forma como falo de sua vocação ontológica para o ser mais, como de sua natureza constituindo-se social e historicamente (FREIRE, 1996, p. 20). 
É fundamental que em toda prática e teoria possamos fundamentar os princípios freireanos, relacionando os sujeitos históricos com a sociedade. Desta forma poderemos analisar a tarefa educativa não como sendo de responsabilidade exclusiva do ensino formal, mas de todos os sujeitos envolvidos no processo histórico. Freire enfatiza, também, a importância da educação para a diversidade, respeitando as diferentes culturas e realidades vividas. $\mathrm{O}$ ato de educar para Freire é um ato de respeito e seriedade, tendo como princípio permanente o agir ético em todas as ações. Freire esclarece a importância da Ética na Educação da seguinte forma:

Gostaria, por outro lado, de sublinhar a nós mesmos, professores e professoras, a nossa responsabilidade ética no exercício de nossa tarefa docente. Este pequeno livro se encontra cortado ou permeado em sua totalidade pelo sentido da necessária eticidade que conota expressivamente a natureza da prática educativa, enquanto prática formadora. Educadores e educandos não podemos, na verdade, escapar à rigorosidade ética. Mas, é preciso deixar claro que a ética de que falo não é a ética menor, restrita, do mercado, que se curva obediente aos interesses do lucro (...) falo da Ética universal dos seres humanos, que condena o cinismo, que condena a exploração da força de trabalho do ser humano (FREIRE, 1996, p. 16-17).

A ética antropocêntrica é criticada por Freire, pois seria um privilégio de poucos e um ato egoísta pensar em seus próprios interesses. A ética universal possibilita vínculos de interesses coletivos e amplos. Somente com a ética universal poderemos atuar a favor de mudanças radicais na sociedade em que vivemos. Mas para que possamos romper com a idéia utilitarista que permeia e condena muitas vezes a nossa atual sociedade capitalista, precisamos de uma articulação permanente entre educandos e educadores, para que possamos nos incumbir da rigorosidade ética.

Por sua vez, Hans Jonas rompe com as bases da ética antropocêntrica e propõe, também, a ética universal com o seu O Princípio Responsabilidade, a fim de abranger todas as formas de vida da biosfera. A teoria da responsabilidade poderá nos ajudar a levantar questões que poderão contribuir para uma Educação Ética. 
Conforme Jonas escreveu no livro Técnica, medicina e ética,

Nem uma ética anterior tinha de levar em consideração a condição global da vida humana e o futuro distante e até mesmo a existência da espécie. Com a consciência de extrema vulnerabilidade da natureza a intervenção tecnológica do homem, surge a ecologia. Repensar os princípios básicos daética. Procurar não só obem humano, mas também o bem de coisas - extra-humanas, ou seja, alargar o conhecimento dos "fins em si mesmos" para além da esfera do homem, e fazer com que o bem humano incluísse o cuidado delas (JONAS, 1997, p. 40).

As doutrinas éticas tradicionais carecem de uma série de atualizações especialmente na medida em que partem das reflexões sobre a condição humana que a modernidade ultrapassou: "quando se aplica à ética liberal, usamos instrumentos antigos e insuficientes para lidar com todos os efeitos negativos e os novos desafios da civilização, seja em termos locais ou globais" (PELIZZOLI, 2003, p. 98).

Hans Jonas iniciou suas reflexões éticas a partir das vivências de desumanização das quais participou, bem como da exploração meio ambiente pelo homem no decorrer dos tempos. Jonas aponta as exigências da ética nos seguintes termos:

Hoje, a ética tem a ver com atos que têm um alcance causal incomparável em direção ao futuro, e que são acompanhados de um saber de previsão que, independentemente do seu caráter incompleto, vai muito além, do que se conhecia antigamente. É preciso acrescentar à simples ordem de grandeza das ações a longo termo, freqüentemente a sua irreversibilidade. Tudo isso coloca a responsabilidade no centro da ética, inclusive os horizontes de espaço e tempo que correspondem aos das ações (JONAS, 1995, p.17).

A ética que Hans Jonas aborda, como ética da responsabilidade, é uma área do conhecimento que se aproxima da bioética, pois prioriza a vida como sendo de plena responsabilidade humana. Hans Jonas determinou O Principio Responsabilidade como sendo uma ética em que o mundo animal, vegetal, mineral, biosfera e estratosfera passam a fazer parte da esfera da responsabilidade. A reflexão sobre a incerteza da vida futura é um sinal de que houve um equívoco cometido ao isolar 
o ser humano do restante da Natureza (sendo o homem a própria Natureza). Somente uma ética fundamentada na amplitude do ser poderia ter um significado real e verdadeiro das coisas. Segundo o autor, para "ser é necessário existir, e para existir é necessário viver e ter deveres, porém, (...) somente uma ética fundada na amplitude do Ser pode ter significado" (JONAS, 2006, p. 17).

Para debatermos assuntos emergentes, como os temas educacionais, necessitamos pensar na construção de uma ética coletiva e universal, que supere o utilitarismo e o antropocentrismo. Entretanto, é importante assumirmos o trabalho com princípios éticos e reflexivos a fim de indagar sobre a radicalidade dos problemas, propondo soluções e alternativas sustentáveis para a vida. A Educação, quando parceira da Filosofia (Ética), tem condições de realizar a emancipação dessa racionalidade, proporcionando um processo de ensino aprendizagem que tenha como princípio ético a responsabilidade.

O Princípio Responsabilidade é um imperativo ético que visa um debate acerca da problemática ambiental do nosso tempo. No entanto, poderíamos indagar: como é possível educar com princípios éticos e responsáveis no contexto de perversidades no qual vivemos? Normalmente, entende-se que é um dever de toda a sociedade educar visando à responsabilidade. Iniciando pelas convicções pessoais e condutas particulares, passando pela família, pela escola, pela comunidade, pelos órgãos privados e públicos e pela gestão política que administra a organização da sociedade. Educar em tempos de crise é um desafio para quem ensina e para quem aprende. Por isso, é fundamental questionar sobre as razões que nos levam a refletir sobre a vida.

Para o educador Paulo Freire, é possível uma educação ética, desde que todos estejam envolvidos no processo educativo e engajados na luta por uma educação transformadora. No processo de construção do conhecimento tal se dá quando todos ensinam e aprendem com suas próprias experiências e histórias de vida. Por isso Paulo Freire lutou por uma ética da diversidade, pois a sociedade deve educar o ser humano para a vida, para os valores, a fim de despertar ações visando a proteção e o respeito à biosfera.

Paulo Freire e Hans Jonas não viveram a intensidade dos avanços da tecnologia dos últimos quinze anos. Porém, percebemos nos escritos 
de Jonas o quanto suas previsões apontavam para o agravamento e à amplitude da relação dos impactos da ação do homem com o meio. Isso nos remete a pensar que se Freire e Jonas estivessem entre nós, a luta pela vida continuaria, partindo da indignação e da "justa raiva" (Freire) ou dos princípios próprias da ética e da responsabilidade.

Pensar na existência é poder pensar nas possibilidades de estarmos "com e no mundo". Se estamos "no mundo" estamos como seres em existência, mas se estamos "com o mundo" estamos na luta pela vida e nos tornaremos testemunhas de nossa própria história. Por isso Freire lembra: "Com a palavra, o homem se faz homem. Ao dizer sua palavra, pois, o homem assume conscientemente sua essencial condição humana" (FREIRE, 1980, p.7). Precisamos ir ao encontro das idéias de Freire. Precisamos educar para a vida, problematizando o ser humano na sua relação com o mundo. Freire argumenta claramente como é importante poder manifestar-se para poder transformar. "A existência, porque humana, não pode ser muda, silenciosa, nem tampouco pode nutrir-se de falsas palavras, mas de palavras verdadeiras, com que os homens transformam o mundo" (FREIRE, 1980, p. 92). O ser humano, como existência, não se torna sujeito de investigação, mas, como essência, torna-se sujeito capaz de refletir criticamente sobre a sua condição humana.

Para o animal, rigorosamente, não há um aqui, um agora, um ali, um amanhã, um ontem, porque carecendo da consciência de si, seu viveré uma determinação total. Nãoé possível ao animal sobrepassar os limites impostos pelo aqui, pelo agora ou pelo ali (FREIRE, 1980, p. 106).

Os animais não admiram o mundo, apenas vivem nele. Por isso a condição irracional não é responsável pelo futuro da humanidade. Mas nós somos responsáveis pelo futuro dos irracionais. Para Freire (1980), a questão fundamental que carece ser trabalhada sempre é a compreensão crítica da "totalidade das coisas", sua interação na totalidade do Planeta Terra. E, para poder transformar, é ontológico o diálogo, pois "o diálogo, como encontro dos homens para a pronúncia do mundo, é uma condição fundamental para a sua real humanização" (FREIRE, 1980, p. 160).

O grande desafio está em poder repensar a educação numa perspectiva emancipatória, enfrentando a fragmentação do conhecimento e a 
conservação de estruturas sociais injustas, fundamentadas em heranças autoritárias. Freire argumenta que precisamos de mudanças educacionais, principalmente no Brasil:

Precisamos hoje no Brasil, talvez mais do que ontem, de uma prática educativa exemplarmente democrática. Precisamos de campanhas realizadas, por exemplo, através de semanas de estudos da democracia em escolas públicas, privadas, universidades, escolas técnicas, sindicatos. Campanhas que encharcassem as cidades de democracia. Semanas em que se apresentasse a história da democracia, em que se debatesse a relação entre democracia e ética, e classes populares, e economia. Eleições, direitos e deveres que elas implicam. Inexperiência democrática brasileira. Democracia e tolerância. Gosto da liberdade e democracia; forças inconciliavelmente contraditórias; forças conciliavelmente diferentes; unidade da diversidade (FREIRE, 2006, p.73).

Paulo Freire sempre ressaltou a importância da participação nas lutas e movimentos sociais, pois essas experiências ajudariam a mudar a compreensão dos fatos. Por isso é fundamental continuar apostando numa educação responsável, que desempenhe o seu papel na sociedade, abrindo espaços de discussões em que sejam explicitadas e analisadas as concepções presentes na atual realidade. Somente assim poderemos construir uma cidadania que privilegie o conhecimento, apontando para a possibilidade de uma maior liberdade e autonomia. A educação, afirma Freire (2006), não pode tudo, mas sem ela a mudança torna-se mais difícil.

Se a educação sozinha não transforma a sociedade, sem ela tampouco a sociedade muda. Se a nossa opção é progressista, se estamos a favor da vida e não da morte, da equidade e não da injustiça, do direito e não do arbítrio, da convivência com o diferente e não de sua negação, não temos outro caminho senão viver plenamente a nossa opção. Encarná-la, diminuindo assim a distância entre o que fizemos e o que fazemos. Desrespeitando os fracos, enganando os incautos, ofendendo a vida, explorando os outros, discriminando o índio, o negro, a mulher não estarei ajudando meus filhos a serem sérios, justos e amorosos da vida e dos outros (FREIRE, 2000, p. 31-32). 
Portanto, é através de uma Educação engajada, com princípios éticos, que o ser humano poderá tornar-se um sujeito consciente e comprometido com as causas emergentes e necessárias para educarmos em tempos de "crise". Mas, para que isso ocorra, é preciso envolver as pessoas, pois a tarefa e o caminho a serem seguidos serão de luta e persistência. É neste emaranhado de certezas e incertezas que nasce a cada dia uma nova esperança, em lugares diferentes, com pessoas diferentes, mas com realidades e preocupações de vida em comum.

Precisamos saber e denunciar as realidades constitutivas de um mundo desumanizado. Freire é exemplo para que possamos continuar lutando e acreditando nas possíveis mudanças e não identificar as grandes causas como luta utópica. O educador Paulo Freire lutou a favor de uma educação solidária e transformadora, tanto que suas idéias se propagaram em todo Brasil e pelo mundo afora. Freire sonhou os bons sonhos e muitos deles foram concretizados. Por isso retomamos Freire para pensar o atual quadro da educação.

Acompanhados de Paulo Freire e Hans Jonas, precisamos de uma educação que problematize e mostre a importância dos sujeitos no mundo e com o mundo; que estimule a reflexão dos sujeitos acerca das realidades vividas, que giram em torno de corrupção, da alienação, e que aposte na valorização de todos os sujeitos envolvidos. Quanto mais problematizarmos e orientarmos o mundo vivido, mais reforçaremos a necessidade de uma educação ética e responsável.

\section{Finalizando...}

Tanto Freire quanto Jonas entendem a ética como um saber que pode ser ensinado e aprendido. Sabemos que a ética e a educação não vão transformar o mundo, mas a transformação não é possível sem a ética e sem a educação. Ou seja, "se a educação quer realmente transformar a realidade não basta intervir na mudança dos comportamentos sem intervir nas condições do mundo em que as pessoas habitam" (CARVALHO, 1992, p. 33).

A reflexão ética na educação implica em poder construir conhecimentos, conceitos e paradigmas. Desta forma, repensar o papel da ética no contexto educacional é primordial. É preciso pensar a ética 
como um conhecimento que deverá ser agregado ao ato de educar. A ética é "a própria essência do ato educativo" (GADOTTI, 2000, p. 81). Precisamos repensar os modelos de sociedades que prevalecem como sendo certos em nosso tempo, bem como sobre o posicionamento das instituições de ensino acerca da educação em tempos de crise.

A tarefa é educar cidadãos capazes de questionar e fundamentar valores radicalmente críticos e éticos. Por isso vai se tornando imperativo aprender a educar visando o processo histórico como umas das explicações sobre o passado, vivendo o presente e pensando o futuro. Por isso, as célebres palavras de Freire servem como uma reflexão a ser feita todos os dias enquanto estivermos na luta: "a educação é indispensável nessa reinvenção. Assumirmo-nos como sujeitos e objetos da História nos torna seres da decisão da ruptura. Seres éticos" (FREIRE, 2006, p. 40).

A tarefa e o caminho a serem seguidos são longos e demandam persistência. Nós, enquanto educadores, temos um compromisso com a educação diante de todas as questões, principalmente as questões sociais e éticas, para que possamos educar para a mudança de compreensão e de ação. É necessário fazer uma reflexão sobre o ato de educar, considerando as divergências em torno do atual debate que cerca o tema da ética. Neste contexto percebemos a importância das discussões próprias da modernidade nas atuais discussões acerca dos rumos da civilização contemporânea. Para Jonas (2006), quanto mais se pressente o perigo do futuro, mais temos que agir no presente. E este é o nosso desafio: educar para a vida.

\section{Notas}

\footnotetext{
* Esse artigo tem origem nos estudos de Mestrado em Educação, realizados por Cláudia Battestin, sob a orientação do Professor Gomercindo Ghiggi, pelo PPGE da UFPel.

${ }^{1}$ Doutoranda em Educação pela UFPel. Mestre em Educação pela UFPel. Especialista em Educação Ambiental pela UFSM. Licenciada em Filosofia pela UNOCHAPECÓ. Participa do Grupo de Pesquisa - Filosofia, Educação e Práxis Social e da Linha de Pesquisa: Filosofia e História da Educação do PPGE da UFPel, E-mail: claudiabattestin@ hotmail.com

${ }^{2}$ Doutor em Educação pela UFRGS. Mestre em Antropologia Filosófica pela PUCRS e Graduado em Filosofia pela UCPel. Participa do Grupo de Pesquisa - Filosofia, Educação e Práxis Social e da Linha de Pesquisa: Filosofia e História da Educação do PPGE da UFPel. Professor do Programa de Pós-Graduação em Educação (Mestrado e Doutorado) da Universidade Federal de Pelotas (UFPel). E-mail: gghiggi@terra.com.br
} 


\section{Referências}

CARVALHO, I.C.M. Educação, meio ambiente e ação política. Rio de Janeiro: IBASE ,1992.

ESTRELA, M. T. Relação pedagógica, disciplina e indisciplina na aula. 3 ed. Porto: Porto Editora, 1998.

FREIRE, Paulo. A sombra desta Mangueira. 8 ed. São Paulo: Olho d'Água, 2006.

. Pedagogia da Indignação. Cartas pedagógicas e outros escritos. São Paulo: UNESP, 2000.

Educação como prática da liberdade. $25^{\mathrm{a}}$ ed. Rio de Janeiro: Paz e Terra, 2001.

. Pedagogia da esperança: um reencontro com a Pedagogia do oprimido. 9. ed. Rio de Janeiro: Paz e Terra, 2002.

- Pedagogia da Autonomia: saberes necessários à prática educativa, 30 ed. Rio de Janeiro: Paz e Terra, 1996.

.Pedagogia do Oprimido. 8 ed. Rio de Janeiro: Paz e Terra, 1980.

GADOTTI, M. Educação e poder: introdução à pedagogia do conflito. São Paulo: Cortez, 1988.

GEORGEN, Pedro. Pós-modernidade, ética e educação: polêmicas do nosso tempo. Campinas: Autores associados, 2001.

JONAS, Hans. El principio del responsabilidad: ensayo de una ética para la civilización tecnológica. Barcelona: Herder, 1995.

O Princípio Responsabilidade. Ensaio de uma ética para uma civilização tecnológica. Rio de Janeiro: PUC Rio, 2006. 
.Técnica, medicina y ética. Barcelona: Paidós, 1997.

\author{
MATURANA, Humberto. Emoções e Linguagem na Educação e \\ na Política. Belo Horizonte, Editora UFMG. 1999.
}
NARANJO, Cláudio. Cambiar la educacion para cambiar el mundo. Providencia:Cuarto proprio, 2007.

\author{
SANTOS, Boaventura de Sousa Os Processos da globalização. \\ Porto: Edições Afrontamento, 2001.
}

\title{
Abstract: \\ Contemporaries reflexions for an ethical and responsible education
}

There are many arguments and possibilities to interlace Ethics with Education. However, this attempt has already reverberated in many areas of knowledge. But how it is possible to near and link the Ethics in Education in the peak of technological development of the XXI century? But how it is possible to approach and connect the Ethics in Education in the peak of technological development of the XXI century? Think in this approach it is a commitment of all the knowledge areas, because we live in a globalized scenario, where everything turns around the technique and the new demands of the market. However, the education could be in tune with the changes of paradigms, avoiding the formation and attitudes that can lean the human being to utilitarianism once more. The Ethics inserted in Education develops in the individual the capacities to establish relationships of responsibility, skills and criticism in actions. By this way, we will argue in respect of the importance in address the Ethics in a universal form and not in the reductionist form. Hans Jonas and Paulo Freire contributed with their writings about the importance in teaching with universal ethics principles, prioritizing the life in all planetary spheres.

Key-Words: Ethics. Education. Responsibility. Hans Jonas and Paulo Freire.

Recebido em agosto de 2009.

Aceito em dezembro de 2009. 